the limb just before and just after totality. Prof. H. F. Newall and Prof. A. Fowler, from observations made in England at the eclipse of April 1912, showed what interesting results might be expected from observations of a nearly total eclipse or from observations at the edge of the belt of totality, confirming suggestions made by Mr. Evershed in 1903. Hitherto bad weather has frustrated all attempts to carry out such investigations, while the interest of the problem has only been increased by the study of spectral changes in wave-length at the sun's limb. Prof. Dingle is using a Littrow spectrograph with two $60^{\circ}$ prisms backed by a plane Rowland grating (used in the first order), working with a $4 \mathrm{in}$. lens of $16 \mathrm{ft}$. focal length. The region of the spectrum to be examined will be $\lambda \lambda 4200-4400$, with an average dispersion of $0.6 \mathrm{~A}$. per $\mathrm{mm}$. The limb will be studied for about five minutes each side of totality, and the cusp for about half an hour beforehand and half an hour afterwards.

(3) The programme of the Cambridge expedition will be mainly a repetition of investigations prevented by clouds at the eclipses of 1927, 1929, in Norway, Siam, and Kedah. The polarisation of the corona will be studied by a double tube camera of $54 \mathrm{in}$. focal length, with a large nicol prism placed in front of one tube. The dependence of the polarisation on wave-length will be examined by a double-image one-prism spectrograph fed by an image-forming lens of $2 \mathrm{ft}$. focal length. The Hills quartz spectrograph will be used for a study of the ultra-violet spectrum of the chromosphere, with especial reference to the intensities at varying solar levels of the lines of the Balmer series and of the continuous spectrum at the head of the series. In the case of the corona, the chief study with this instrument will be the distribution of the radiation of the continuous spectrum. The results obtained with this spectrograph will be checked by a spectrum of different dispersion obtained from a 6 in. concave Rowland grating, used in the stigmatic position with a reflecting collimator. The range of spectrum to be covered will be $\lambda \lambda 3200-4600$.

The continuous spectrum of the outer corona will be studied with a 19-inch Common mirror of 50 in. focal length and a one-prism spectrograph with Aldis collimator and camera lenses of aperture $4 \mathrm{in}$. working at $f / 3$. An objective interferometer will be used to study the wave-length of the green coronal line and movements in the coronal gases, in particular the rotation of the corona. The latter problem will also be attacked with the 4-prism spectrograph mounted on a polar-heliostat and used for that purpose by Prof. Newall in Sumatra in 1901.

A moving plate objective grating spectrograph with a slit in the focal plane radial to the sun's limb will be used for spectrophotometric study of the flash spectrum at different levels over the range $\lambda \lambda 4100-4700$. The grating will be a 6 in. plane grating fed by a Cooke photovisual lens of 6 in. aperture and $20 \mathrm{ft}$. focal length. A second objective grating will, it is hoped, be used for plates stained with xenocyanin and sensitive over the range $\lambda \lambda 8600-10600$, while a slit grating spectrograph will be used with plates stained with mesocyanin for the region centred at $\lambda 8600$. The various instruments are being fed with beams from two colostats and Sir Francis McClean's 21-in. siderostat. The Hills siderostat will be used by the observers from McGill University for a grating spectrograph of high light-gathering power.

Finally, the 8 in. cœlostat of the Royal Irish Academy will feed the $4 \mathrm{in}$. lens of $19 \mathrm{ft}$. focal length lent by the same body, to secure direct photographs of the corona, and the $4 \mathrm{in}$. directvision prism of the Royal Observatory, Edinburgh, will be placed in front of the lens at the beginning and end of totality for objective-prism spectra of the flash, while Dr. Lockyer will take direct photographs of the corona with a camera lens of 4 in. aperture and $28 \mathrm{in}$. focal length.

\title{
The Lucasian Professors at Cambridge
}

$\mathrm{T}$ HE Lucasian professorship of mathematics at the University of Cambridge, from which Sir Joseph Larmor retires at the end of September after holding it with distinction since 1903, is the third oldest chair of mathematics in Great Britain. The chair of geometry at Gresham College, London, was founded in 1596, the Savilian professorship of geometry at Oxford dates from 1619, while the Lucasian chair was founded in 1663, the same year in which the Royal Society received its second charter. It was founded through a bequest by Henry Lucas, who had studied at St. John's College, Cambridge, and after having served as secretary to the Earl of Holland, chancellor of the University, was elected to represent the University in Parliament. In his will he directed his executors to purchase land to the value of $£ 100$ a year to provide for the stipend of a professor of mathematics. Lucas died in London on July 22, 1663, and that same year the deeply learned and much travelled
Rev. Isaac Barrow (1630-1677), already professor of Greek and Gresham professor of geometry, and afterwards master of Trinity, was elected first Lucasian professor.

Barrow took his duties seriously from the first, and immediately after his appointment, " the better to secure the End of so noble and useful a Foundation, he took Care that himself and his Successors should be obliged to leave, yearly, to the University ten written lectures ". His opening oration was delivered on March 14, 1664, and the lectures he gave during the next five years formed the substance of his "Lectiones Opticæ et Geometricæ", 1669, and his "Lectiones Mathematicæ ", published six years after his death. But divinity had stronger claims for Barrow than even mathematics, and having already seen and acknowledged the superior abilities of his pupil Newton, in 1669 he resigned in his favour.

Newton was twenty-seven years of age when 
he became Lucasian professor, and he held the chair for thirty-four years, until in 1703 he became president of the Royal Society. It is unnecessary to say that it was during his years at Cambridge that all his greatest discoveries were made and his greatest works published. Some of his discoveries were first made known through his lectures. "During his tenure of the professorship", says Ball, "it was Newton's practice to lecture publicly once a week, for from half an hour to an hour at a time, in one term of each year, probably dictating his lectures as rapidly as they could be taken down. . . . He never repeated a course, which usually consisted of nine or ten lectures. . . . The manuscripts of his lectures for seventeen out of the first eighteen years of his tenure are extant."

Newton was elected Parliamentary representative for the University of Cambridge in 1688, and after that lectured but little. In 1699 he made Whiston his deputy, and four years later Whiston was appointed to the chair.

With Newton's resignation and his removal to London, mathematical studies in Cambridge suffered a loss which the University felt for very many years. "Newton's burst of illumination", wrote the late Prof. H. H. Turner, "was followed by a dark century in Cambridge mathematies which is painful to contemplate." Yet in spite of this, the chair on which Newton had shed so much Iustre continued to be held by men who at least had a deep reverence for his character and his work, and each of whom in his turn did something to advance the progress of science.

William Whiston (1667-1752), the first of the five occupants of the Lucasian chair during the eighteenth century, had graduated at Clare Hall and at the time of his appointment was rector of Lowestoft. Something of his activities can be gleaned from his own whimsical memoirs. As Lucasian professor he was instrumental in getting Roger Cotes (1682-1716) made the first Plumian professor of astronomy, declaring that in mathematics he "was but a child to Mr. Cotes", and in 1707 with Cotes he began a course of philosophical experiments. But Whiston's period of office was cut short through his religious views being held obnoxious by the authorities, and on Oct. 30,1710 , he was expelled from the University. The loss of $£ 100$ a year was, no doubt, felt severely, but thanks to Addison and Steele he was able to give astronomical lectures " at Mr. Button's Coffee house, near Covent Garden, to the agreeable entertainment of a good number of curious persons and the procuring me and my family some comfortable support under my banishment".

The choice of a successor to Whiston fell on Nicolas Saunderson (1682-1739), who through smallpox had been blind from the age of one, but who was described by one of his students as "a professor who had not the use of his own eyes, but taught others to use theirs". He was one of the earliest exponents of the Newtonian philosophy and, it is said, spent seven or eight hours a day in teaching. His "Elements of Algebra", compiled during the last six years of his life, has been referred to as "a model of careful exposition". John Colson (1680-1760), who succeeded Saunderson,-was already fifty-nine when appointed to the chair; he had had as a competitor Demoivre, the intimate of Newton, who, however, was seventy - two, "almost as much fit for his coffin; he was a mere skeleton, nothing but skin and bone". In 1736, Colson had published a work on fluxions, and during the twenty-one years he held the Lucasian professorship he translated Nollet's work on experimental philosophy and Maria Gaetana Agnesi's "Istituzioni analitiche", but, said Cole, the Cambridge antiquarian, "the University was much disappointed in its expectations of a professor that was to give credit to it by his lectures ".

When Colson died in 1760 at the age of eighty years, the example of Barrow and Newton was no longer followed, and neither Edward Waring (17341798) nor Isaac Milner (1751-1820), his successors, gave lectures or enriched the University with their writings. Waring was only twenty-five years of age when given the Lucasian chair. Afterwards he qualified in medicine and obtained a seat on the Board of Longitude, but his European fame was due to his "Miscellanea Analytica" and his contributions to the Philosophical Transactions of the Royal Society, for which in $\mathbf{1 7 8 4}$ he was awarded the Copley Medal. Milner was both man of science and a divine, and became president of Queens' College, Cambridge, and Dean of Carlisle. Born in 1751 , he was senior wrangler and Smith's prizeman in 1774, studied chemistry under Watson, and in 1783 became the first Jacksonian professor of natural philosophy. Resigning this post in 1792 , " henceforth", it is said, "he gave up science in general except as an amusement". He had written works on motion, equations, the precession of the equinoxes, and natural philosophy, but after being appointed to the Lucasian chair on Waring's death in 1798, he contented himself with carrying out the minor duties of the post without doing any teaching.

It was while Milner held the chair that the writings and mèthods of the continental mathematicians began to be studied seriously at Cambridge, and with this came the reformation of mathematical studies not only in the University but also in the whole country. Foremost among the reformers was Robert Woodhouse (1773-1827), fellow of Caius College, who in 1803 published his "Principles of Analytical Calculations", and was chosen as Milner's successor in 1820. He held the chair for only two years, and within the next few years the chair was held by three different incumbents. From 1822 to 1826 it was occupied by Thomas Turton (1780-1864), a senior wrangler, who became professor of divinity, Bishop of Ely, and Dean of Westminster; during 1826-28 it was held by George Biddell Airy (1801-92), who vacated it to become Plumian professor of astronomy, a post he held until he was made Astronomer Royal ; and in 1828 it was given to Charles Babbage (1792-1871).

With Herschel and Peacock, Babbage in 1813

No. 3273 , VoL. 130] 
had founded the Analytical Society at Cambridge, and in 1816 had translated Lacroix's "Traité élémentaire du calcul différentiel et du calcul intégral ", thus ably furthering the movement begun by Woodhouse. It was the combined efforts of these four which paved the way for what has been called "the golden age of mathematics and physies at Cambridge". But, by 1828 , Babbage was too deeply engrossed in his calculating machine to devote much time to the duties of a professor, and though he was sensible of the honour conferred upon him, "the only honour", he wrote, "I ever received in my own country ", he contented himself with performing his duties as an examiner. As such he exerted considerable influence, and among the winners of Smith's prize examined by him was William Cavendish, afterwards Duke of Devonshire, chancellor of the University, and the founder of the Cavendish Laboratory.
Babbage held office for eleven years, when he was succeeded by Dr. Joshua King (1798-1857), who from 1832 until 1857 was president of Queens' College. By this time the new school of Cambridge mathematicians included many who were destined to become famous, and during the ten years Dr. King held the Lucasian chair, among the names of the senior wranglers and Smith's prize-winners were those of Ellis, Cayley, Adams, Todhunter, Kelvin, and Stokes, the last of whom in 1849, at the age of thirty, was chosen to succeed Dr. King. On the work of Sir George Gabriel Stokes (1819-1903), the immediate predecessor of Sir Joseph Larmor, it is unnecessary to dwell. During the fifty-four years of his tenure of the chair, he re-established the fame of the office once held by Barrow and Newton, and on the occasion of his scientific jubilee he was hailed as "the Newton of the nineteenth century".

\section{Centenary of The British Medical Association*}

$\mathrm{T}$ HE British Medical Association, which is celebrating the centenary of its foundation at its annual meetings in London on July 21-29, is fortunate in having secured a chronicler worthy of the occasion in the person of Mr. Muirhead Little, who is not only a distinguished orthopædic surgeon but is also a well-known and accomplished writer on medical history. His work contains a very full and well-written description of the history of the British Medical Association and its multifarious activities during the last hundred years, together with an account of the leading personalities connected therewith.

Mr. Muirhead Little begins with a sketch of the medical profession in 1832, a year memorable not only for the foundation of the Provincial Medical and Surgical Association, as the British Medical Association was first called, but also for the first epidemic of Asiatic cholera in England, the Anatomy Act, and the First Reform Bill. In the absence of statistical information, the sciences of epidemiology and public health did not then exist, and indeed, until the passing of the Registration Act in 1836, there were no national statistics to justify any trustworthy conclusions. The profession as a whole was not organised, for there was no hard and fast line between the qualified and unqualified practitioner, and it was not until the Medical Act of 1858 , which was almost entirely the work of the Association, that the great body of practitioners first received official recognition of their existence, and their importance to the State was acknowledged. The average medical practitioner in 1832 was a man of little culture or education, and there seems to have been ample justification for the unattractive picture of the contemporary medical student drawn by Dickens in "The Pickwick Papers" and by Thackeray in "Pendennis".

Dr. Charles Hastings, on the other hand, the

\footnotetext{
* History of the British Medical Association, ]832-1932. Complled by Ernest Muirhead Little. Pp. vili $+342+29$ plates. (London: British Medical Association, 1932.)
}

No. 3273 , VoL. 130] founder of the Association, who was knighted in 1850 , was a man of considerable abilities, some originality of mind, and great industry. At the early age of thirty-four years, he became the leading physician in Worcester, as well as being an eminent naturalist. In $\mathbf{1 8 2 8}$ he founded the Midland Medical and Surgical Reporter and Topographical and Statistical Journal, which came to an end in 1832, being succeeded in 1840 by the Provincial Medical and Surgical Journal, the organ of the Association, which during the period $1832-40$ had published only an annual volume of Transactions. It was not until 1856 that the Association, which had hitherto been known as the Provincial Medical and Surgical Association, received its present name, while its organ, which had been renamed the Association Medical Journal in 1853, was given its present title of the British Medical Journal at the beginning of 1857 .

The scientific work of the Association, of which Mr. Muirhead Little gives a very full description, has formed an important part of its activities since its foundation. This work includes the discussion of scientific topics distributed over fourteen to twenty sections at its annual meetings; the dissemination of information in the British Medical Journal and the special journals, the Archives of Disease in Childhood and the Journal of Neurology and Psychopathology; the appointment from time to time of special committees to consider particular aspects of medical science; the arrangement of collective investigations throughout the profession; the award of scholarships, grants, and prizes; and the organisation of lectures, both among members of the profession and the lay public. Moreover, the local units, of which there are several hundreds, devote a great part of their energy to the consideration of scientific questions.

The work carried out by special scientific com. mittees of the Association during the last fifty years includes reports on chloroform, the action of various drugs, the prevention of ophthalmia neonatorum, 